\title{
Repetitive extragenic palindromic DNA sequences from Brucella melitensis stimulate Toll-like receptor 9 signaling in macrophages
}

\author{
HUI YU ${ }^{1,2^{*}}$, LIYUN BAI $^{3 *}$, YAXIAN ZHANG ${ }^{4}$, ZHANLI WANG ${ }^{3,4}$ and YONGCHUN YU ${ }^{1}$ \\ ${ }^{1}$ Central Laboratory, Shanghai Municipal Hospital of Traditional Chinese Medicine, \\ Shanghai University of Traditional Chinese Medicine, Shanghai 200071; ${ }^{2}$ Department of Laboratory Medicine, \\ The Second Affiliated Hospital, Baotou Medical College, Baotou 014030; ${ }^{3}$ Department of Laboratory Medicine, \\ The First Affiliated Hospital, Baotou Medical College, Baotou 014010; ${ }^{4}$ Department of Epidemiology, \\ School of Public Health, Baotou Medical College, Baotou 014060, P.R. China
}

Received August 18,2015; Accepted May 24, 2016

DOI: $10.3892 / \mathrm{mmr} .2016 .5990$

\begin{abstract}
Brucella DNA activates the host innate immune system via the intracellular Toll-like receptor 9 (TLR9). However, the Brucella DNA sequences which are responsible for these immunostimulatory effects remain to be elucidated. The present study demonstrated that repetitive extragenic palindromic (REPs) sequences present in Brucella DNA were able to stimulate macrophages through TLR9. The induction of interferon- $\alpha$ (IFN- $\alpha)$ production by Brucella REPs was detected in cultured RAW264.7 mouse macrophages as well as in Wistar rats. Knockdown of TLR9 expression by siRNA in macrophages led to a reduction in IFN- $\alpha$ production following REPs stimulation. In addition, it was confirmed that the activating capacity of Brucella REPs is CpG dependent. Induction of IFN- $\alpha$ by Brucella REPs was completely abrogated when REP sequences were transformed into non- $\mathrm{CpG}$ sequences or by C-methylated modifications. Furthermore, it was observed that REPs-initiated TLR9/NF- $\kappa$ B and TLR9/MAPK signaling pathways contributed to the production of IFN- $\alpha$. The identification of Brucella REPs as natural TLR9 agonists may be useful for the development of novel therapeutic applications.
\end{abstract}

Correspondence to: Professor Zhanli Wang, Department of Laboratory Medicine, The First Affiliated Hospital, Baotou Medical College, 41 Linyin Road, Baotou 014010, P.R. China

E-mail: wang.zhanli@hotmail.com

Professor Yongchun Yu, Central Laboratory, Shanghai Municipal Hospital of Traditional Chinese Medicine, Shanghai University of Traditional Chinese Medicine, 274 Middle Zhijiang Road, Shanghai 200071, P.R. China

E-mail: yyc@tongji.edu.cn

${ }^{*}$ Contributed equally

Key words: Brucella, repetitive extragenic palindromic sequence, Toll-like receptor 9

\section{Introduction}

Innate immunity serves as the first line of defense against microbial pathogens (1). Toll-like receptors (TLRs) are essential sensor molecules of the host innate immune system. They detect various pathogen-associated molecular patterns and initiate innate immune responses via distinct signaling pathways (2). TLR9 is a member of the TLR family (3). It recognizes specific bacterial DNA sequences containing unmethylated cytidine-phosphate-guanosine $(\mathrm{CpG})$ motifs, leading to activation of downstream signaling pathways, including nuclear factor- $\kappa \mathrm{B}(\mathrm{NF}-\kappa \mathrm{B})$ and mitogen-activated protein kinase (MAPK). Activation of these signaling pathways induces the production of type I interferon (IFN) and other cytokines that influence the immune response against infectious agents $(4,5)$. Previous studies have demonstrated that synthetic phosphorothioate oligodeoxynucleotides (ODN) bearing unmethylated CpG motifs may mimic the TLR9-dependent immune-stimulatory effects of bacterial DNA $(6,7)$. These studies permitted development of the structure-immunostimulatory activity relationship of synthetic CpG ODN. However, the features of natural bacterial sequences with immunostimulatory potential remain to be elucidated.

Brucella species are gram-negative, facultative intracellular bacteria (8). A total of 4 species of the genus Brucella are pathogenic for humans, namely B. melitensis, B. abortus, B. suis and B. canis. B. melitensis is considered to be the most pathogenic (9). Brucella is able to survive and replicate inside host macrophages and dendritic cells (10). In recent years it has become apparent that Brucella DNA has an essential role in the triggering of the innate immune system (11). Immunostimulatory effects of Brucella DNA are exerted via TLR9 $(12,13)$.

It is well-known that repetitive extragenic palindromes (REPs) are small (20-40 bp) palindromic repeats, present in high copies in gram-negative bacteria. They are important for regulation of certain bacterial functions, including DNA supercoiling, transcription termination and mRNA stabilization (14). A previous study demonstrated that REP sequences 
are natural TLR9 ligands (15). Studies with REP sequences have determined the structural features of bacterial immunostimulatory DNA sequences (15). To the best of our knowledge, little work has been carried out concerning Brucella REP candidates as natural TLR9 ligands.

The aim of the present study was to identify Brucella REP sequences that have an important role in IFN- $\alpha$ responses in macrophages by binding to TLR9. The interaction between TLR9 and REPs was also investigated. Furthermore, it was examined whether NF- $\mathrm{B}$, c-Jun N-terminal kinase (JNK), extracellular signal-regulated kinase (ERK) 1/2 and p38 were involved in TLR9 signaling stimulated by Brucella REPs in macrophages. These data may be critical to the understanding of how Brucella activates immune responses.

\section{Materials and methods}

Identification and synthesis of REPs. The present study used a BLAST-based strategy specifically designed to detect REPs as described previously (15). The genome analyzed was B. melitensis NI (chromosome 1: Genbank CP002931.1, RefSeq NC_017248.1; chromosome 2: Genbank CP002932.1, RefSeq NC_017283.1). The studied REPs (Table I) were selected from the REPs identified in B. melitensis based on the presence of self-complementary sequences and $\mathrm{CpG}$ motifs. Purified phosphorothioate ODNs representing the selected REPs were synthesized by Sangon Biotech Co., Ltd. (Shanghai, China). For methylated ODN synthesis, 5-methylcytidine was used (Sangon Biotech Co., Ltd.).

Cell culture. Murine RAW264.7 macrophages (Cell Resource Center, IBMS, CAMS/PUMC, Beijing, China) were cultured in Dulbecco's modified Eagle's medium (Gibco; Thermo Fisher Scientific, Inc., Waltham, MA, USA) supplemented with $10 \%$ fetal bovine serum and $1 \%$ penicillin/streptomycin at $37^{\circ} \mathrm{C}$ in a $5 \% \mathrm{CO}_{2}$ atmosphere. Following two passages, cells were seeded into 24 -well plates at a density of $2.0 \times 10^{6}$ cell $/ \mathrm{ml}$.

Treatment of macrophages with ODNs. ODNs were diluted in Opti-MEM (Invitrogen; Thermo Fisher Scientific, Inc.) supplemented with lipofectin $(10 \mu \mathrm{g} / \mathrm{ml}$; Invitrogen; Thermo Fisher Scientific, Inc.). The mixture was incubated at room temperature for $5 \mathrm{~min}$ and then added to each well of the 24-well plate. Culture supernatants were collected at $24 \mathrm{~h}$. A class stimulatory CpG ODN2216 (Sangon Biotech Co., Ltd.) was used in the present study as a positive control. C-methylated ODN2216 (Sangon Biotech Co., Ltd.) was used as a negative control.

Transfection of macrophages with anti-TLR9 small interfering RNA (siRNA). The siRNA sequence used for silencing of murine TLR9 and the negative control siRNA sequence (scrambled siRNA) were synthesized by Invitrogen (Thermo Fisher Scientific, Inc.). Transfection compounds were prepared by adding siRNAs to $95 \mu \mathrm{l}$ Opti-MEM and $5 \mu \mathrm{l}$ HiPerFect (Qiagen $\mathrm{GmbH}$, Hilden, Germany) to give a final concentration of $100 \mathrm{nM}$. The prepared transfection compounds were placed at room temperature for $10 \mathrm{~min}$. RAW264.7 macrophages were then transfected with these transfection mixes in 24-well plates. A total of $48 \mathrm{~h}$ after transfection, the silencing effect of siRNA was detected by western blotting. RAW264.7 cells were then stimulated with ODN1 for $24 \mathrm{~h}$ for use in subsequent experiments.

Animals and ODN treatment. Female Wistar rats aged 6-8 weeks were purchased from Vital River Lab Animal Technology Co., Ltd (Beijing, China). Rats were housed in temperature $\left(20 \pm 2^{\circ} \mathrm{C}\right)$ and humidity $(55 \% \pm 5)$ controlled rooms, with a 12-h light/dark cycle. Animal studies were performed under conditions approved by the Local Animal Care and Use Committee. Rats were injected subcutaneously with $20 \mathrm{mg} / \mathrm{kg}$ ODNs. Serum was collected for ELISA by retro-orbital bleeding $2 \mathrm{~h}$ after injection.

Cytokine ELISA. Concentrations of cytokines in the culture supernatants or serum were measured using ELISA kits according to the manufacturer's protocol (R\&D Systems Inc., Minneapolis, MN, USA). Samples were tested, in duplicate, a total of three times.

Reverse transcription-polymerase chain reaction (RT-PCR) of RNA expression. Total RNA was isolated from RAW264.7 cells using TRIzol reagent (Invitrogen; Thermo Fisher Scientific, Inc.) according to the manufacturer's protocol. RNA was reverse transcribed into complementary DNA using $10 \mu \mathrm{l}$ PrimeScript RT Enzyme Mix I (Takara Biotechnology Co., Ltd., Dalian, China) under the following conditions: $37^{\circ} \mathrm{C}$ for $15 \mathrm{~min}$, followed by $85^{\circ} \mathrm{C}$ for $5 \mathrm{sec}$. One-step semiquantitative RT-PCR (Takara Biotechnology Co., Ltd.) was performed at $95^{\circ} \mathrm{C}$ for $30 \mathrm{sec}$, followed by 40 cycles of $95^{\circ} \mathrm{C}$ for $5 \mathrm{sec}$ and $60^{\circ} \mathrm{C}$ for $30 \mathrm{sec}$. Melting curve analysis of amplification products was performed at the conclusion of each PCR. GAPDH served as an internal control. The sequences of primers were as follows: TLR9 forward, 5'-TTG GTC GC ACC TCC AAC AGT-3' and reverse, 5'-TGG GCC CAT TGT GAT GAA C-3'; GAPDH forward, 5'-TCA ACG GCA CAG TCA AGG-3' and reverse, 5'-ACT CCA CGA CAT ACT CAG C-3' (Sangon Biotech Co. Ltd.).

Western blot analysis. RAW264.7 cells treated with ODNs were harvested and treated with radioimmunoprecipitation assay buffer (BioVision, Inc., Milpitas, CA, USA) supplemented with protease inhibitor cocktail (cOmplete ${ }^{\mathrm{TM}}$ Mini protease inhibitors; Roche Diagnostics, Basel, Switzerland) for $15 \mathrm{~min}$ at $4^{\circ} \mathrm{C}$. The cell lysates $(20 \mu \mathrm{g}$ of protein) were subjected to $10 \%$ SDS-PAGE and then transferred onto a nitrocellulose membrane (Sangon Biotech Co., Ltd.). The membrane was blocked with $5 \%$ nonfat milk in TBST (Triton X-100 0.5\% and Tris-buffered saline), and incubated with primary antibodies, including rabbit anti-mouse phosphorylated (p)-inhibitor of $\kappa \mathrm{B}$ (IкB) $\alpha$ monoclonal antibody (dilution, 1:1,000; catalog no., \#2859), rabbit anti-mouse IкB $\alpha$ polyclonal antibody (dilution, 1:1,000; catalog no., \#9242), rabbit anti-mouse $\mathrm{p}-\mathrm{NF}-\kappa \mathrm{B}$ polyclonal antibody (dilution, 1:1,000; catalog no., \#3031), rabbit anti-mouse NF-кB monoclonal antibody (dilution, 1:1,000; catalog no., \#8242), rabbit anti-mouse p-JNK polyclonal antibody (dilution, 1:1,000; catalog no., \#9251), rabbit anti-mouse JNK polyclonal antibody (dilution, 1:1,000; catalog no., \#9252), rabbit anti-mouse p-ERK1/2 polyclonal antibody (dilution, 1:1,000; catalog no., \#9101), rabbit anti-mouse ERK1/2 polyclonal antibody 
Table I. REP and control sequences.

\begin{tabular}{|c|c|c|}
\hline Study designation & Name & Sequence, $5^{\prime} \rightarrow 3^{\prime}$ \\
\hline ODN 1 & B. melitensis REP & $\underline{\text { AGCGCAGTGATCCGCACCGCGCT }}$ \\
\hline ODN 2 & B. melitensis $\mathrm{REP}^{\text {methyl }} \mathrm{CpG}$ & $\mathrm{AG}^{\mathrm{m}} \mathrm{CGCAGTGATC}{ }^{\mathrm{m}} \mathrm{CGCAC}^{\mathrm{m}} \mathrm{CG}^{\mathrm{m}} \mathrm{CGCT}$ \\
\hline ODN 3 & B. melitensis REP non-CpG & AGGCCAGTGATCAGCACAGGCCT \\
\hline Positive control & ODN2216 & ggGGGACGATCGTCgggggg \\
\hline Negative control & ODN2216 ${ }^{\text {methyl }} \mathrm{CpG}$ & ggGGGAGCATGCTAgggggg \\
\hline
\end{tabular}

Lower case letters denote phosphorothioate and upper case letters denote phosphodiester linkages between nucleotides. CpGs are in bold, and palindromes are indicated by underlining in the sequence. REP, repetitive extragenic palindromic; ODN, oligodeoxynucleotide; $B$. melitensis, Brucella melitensis; ${ }^{\mathrm{m}} \mathrm{C}$, methylated cytosine.

(dilution, 1:1,000; catalog no., \#9102), rabbit anti-mouse p-p38 polyclonal antibody (dilution, 1:1,000; catalog no., \#9211), rabbit anti-mouse p38 polyclonal antibody (dilution, 1:1,000; catalog no., \#9212), rabbit anti-mouse $\alpha$-tubulin polyclonal antibody (dilution, 1:1,000; catalog no., \#2144; all from Cell Signaling Technology, Inc., Danvers, MA, USA), and rabbit anti-mouse TLR9 polyclonal antibody (dilution, 1:500; catalog no., \#TA306291; OriGene Technologies, Rockville, MD, USA), followed by a horseradish peroxidase-conjugated goat anti-rabbit IgG secondary antibody (dilution, 1:5,000; catalog no., \#D110058; Sangon Biotech Co., Ltd.). Immunoreactivity was visualized by enhanced chemiluminescence (ECL kit; Santa Cruz Biotechnology, Inc., Dallas, TX, USA) with the ChemiDoc $^{\mathrm{TM}}$ XRS+ system (Bio-Rad Laboratories, Inc., Hercules, CA, USA).

Molecular modeling. The crystal structure of mouse TLR9 was obtained from the Protein Data Bank (PDB Code: 3WPG) (16). The CpG ODN structure was built using Biopolymer tools in Discovery Studio version 2.5 (Accelrys, San Diego, CA, USA). The program Hex 6.1 (hex.loria.fr/dist61) was used to perform a rigid-body docking search as previously described (17).

Statistical analysis. Multiple groups were compared using one-way analysis of variance, followed by the Fisher's least significant difference test. All data were expressed as the mean \pm standard deviation and $\mathrm{P}<0.05$ was considered to indicate a statistically significant difference.

\section{Results}

ODN1 induces IFN- $\alpha$ production in vitro. The effects of ODNs on IFN- $\alpha$ secretion by macrophages in vitro were determined (Fig. 1). As presented in Fig. 1A, ODN1 significantly enhanced the release of IFN- $\alpha$ at $24 \mathrm{~h}(22.706 \pm 1.305 \mathrm{pg} / \mathrm{ml})$ as compared to the negative control $(10.032 \pm 1.251 \mathrm{pg} / \mathrm{ml})$ $(\mathrm{P}<0.001)$. However, ODN2 and ODN3 induced only low levels of IFN- $\alpha(10.627 \pm 1.237$ and $10.831 \pm 1.012 \mathrm{pg} / \mathrm{ml}$, respectively) compared with the negative control group $(\mathrm{P}=0.589$ and $\mathrm{P}=0.438$, respectively; Fig. $1 \mathrm{~A})$.

ODN1 induces IFN- $\alpha$ production in vivo. The effects of ODNs on serum IFN- $\alpha$ levels in vivo were also determined. Significantly higher serum IFN- $\alpha$ levels were observed in the
ODN1 group $(45.839 \pm 2.103 \mathrm{pg} / \mathrm{ml})$ compared with the negative control group $(12.901 \pm 1.227 \mathrm{pg} / \mathrm{ml})$ at $2 \mathrm{~h}(\mathrm{P}<0.01$; Fig. 1B). However, production of IFN- $\alpha$ remained low in the ODN2 and ODN3 groups $(13.303 \pm 2.478$ and $14.167 \pm 1.221 \mathrm{pg} / \mathrm{ml}$, respectively) compared with the negative control group $(\mathrm{P}=0.815$ and $\mathrm{P}=0.274$, respectively; Fig. 1B).

Effects of anti-TLR9 SiRNA on IFN- $\alpha$ response to ODN1 in macrophages. RAW264.7 cells transfected with anti-TLR9 siRNA or control siRNA were stimulated by ODN1. As presented in Fig. 1C, significantly lower IFN- $\alpha$ levels were observed in the anti-TLR9 siRNA group $(12.253 \pm 0.873 \mathrm{pg} / \mathrm{ml})$ compared to the untransfected $(23.819 \pm 1.012 \mathrm{pg} / \mathrm{ml})$ and control siRNA-transfected $(23.107 \pm 1.238 \mathrm{pg} / \mathrm{ml})$ groups $(\mathrm{P}<0.001)$.

Effects of ODN1 on TLR9 expression. As presented in Fig. 2A, ODN1 enhanced the mRNA expression of TLR9. In addition, the protein expression levels of TLR9 were increased in the ODN1 group (Fig. 2B). However, TLR9 mRNA and protein expression levels were not increased following stimulation with ODN2 and ODN3 (Fig. 2B).

TLR9-ODN1 interaction analysis. The interaction pattern demonstrated that the interface between TLR9 and ODN1 was geometrically complementary (Fig. 3A). Analysis revealed that $>20$ residues in TLR 9 constituted the active site where ODN1 binds (Fig. 3B). Most of these amino acid residues are basic and have an essential role in TLR9-ODN1 interaction, including Lys95, Lys181, Lys207, Arg256, Lys292 and Lys338.

Effects of $O D N 1$ on the $I \kappa B / N F-\kappa B$ signaling pathway. To investigate whether the $\mathrm{I} \kappa \mathrm{B} / \mathrm{NF}-\kappa \mathrm{B}$ signaling pathway in RAW264.7 cells was affected by ODN1, the phosphorylation levels of NF- $\kappa \mathrm{B}$ and I $\kappa \mathrm{B}-\alpha$ in ODN1-treated macrophage cultures were assessed by western blot analysis. As presented in Fig. 4A, the protein expression of p-NF- $\kappa \mathrm{B}$ p 65 was upregulated following 60 and 120 min stimulation with ODN1. However, the expression of p-IкB- $\alpha$ was reduced (Fig. 4A).

Effects of ODN1 on the MAPK signaling pathway. The expression of p-JNK, p-p38 and p-ERK1/2 in ODN1-stimulated RAW264.7 cells was also assessed. As presented in Fig. 4B, an increased phosphorylation of JNK was induced by ODN1 
A

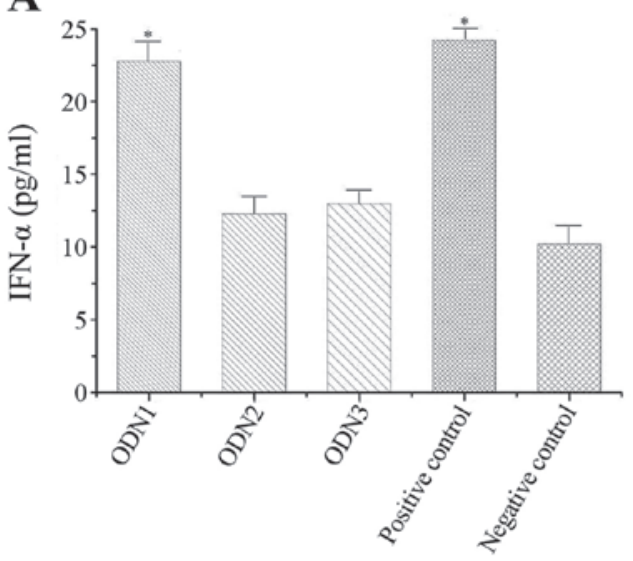

B

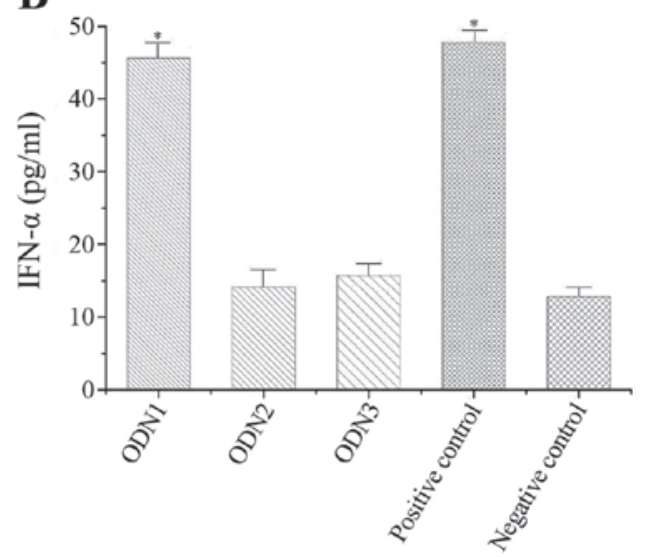

C

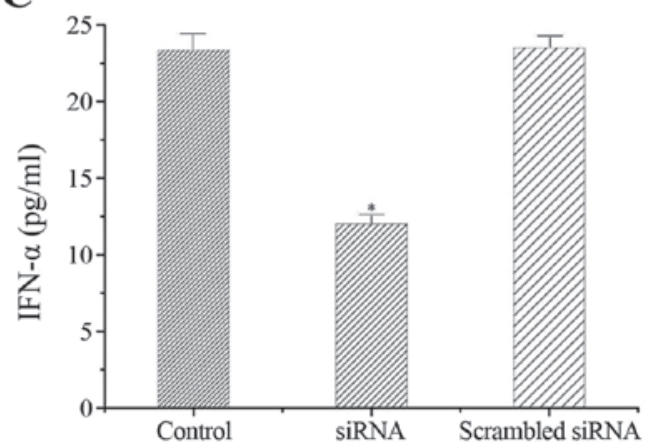

Figure 1. Effects of ODNs on IFN- $\alpha$ secretion. (A) IFN- $\alpha$ profile of ODN-transfected macrophages. IFN- $\alpha$ production was strongly stimulated by ODN1 compared with the negative control. ${ }^{*} \mathrm{P}<0.05$, compared with the negative control. (B) IFN- $\alpha$ profile of serum samples from ODN-treated rats. Significantly higher IFN- $\alpha$ production was induced by ODN compared with the negative control group. * $\mathrm{P}<0.05$, compared with the negative control. (C) Effects of siRNA-mediated knockdown of TLR9 upon ODN1-induced IFN- $\alpha$ secretion in macrophages. IFN- $\alpha$ production was strongly stimulated by the control siRNA-transfected group compared with the anti-TLR9 siRNA group, indicating that ODN1-induced production of IFN- $\alpha$ is TLR9 dependent. ${ }^{*}<0.05$, compared with the control. ODN, oligodeoxynucleotide; IFN- $\alpha$, interferon- $\alpha$; siRNA, small interfering RNA; TLR9, toll-like receptor 9.

A

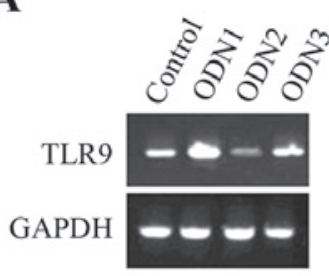

B

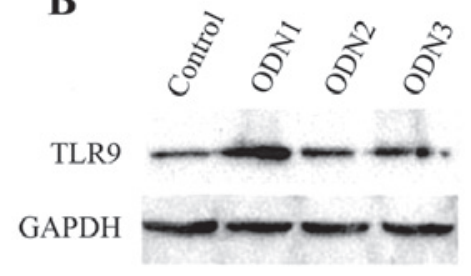

Figure 2. Protein and mRNA expression levels of TLR9 in ODN-transfected macrophages. (A) TLR9 mRNA expression levels. (B) TLR9 protein expression levels. ODN 1 enhanced the mRNA and protein expression levels of TLR9. GAPDH served as the loading control. ODN, oligodeoxynucleotide; TLR9, toll-like receptor 9 .

treatment. Furthermore, phosphorylation of $\mathrm{p} 38$ and ERK1/2 was observed. The levels of p-p38 and p-ERK $1 / 2$ were further increased at $120 \mathrm{~min}$ in ODN1-treated macrophages.

\section{Discussion}

REP sequences, which are palindromic and rich in unmethylated $\mathrm{CpG}$ motifs, are important for the immune recognition of bacteria (18). However, whether REP sequences derived from the Brucella genome exert immunostimulatory effects remains to be elucidated.

In the present study, synthetic ODNs with a natural phosphodiester backbone were utilized to mimic natural REPs. ODNs representing Brucella REP sequences were tested for their ability to stimulate production of the cytokine IFN- $\alpha$ in vitro and in vivo. It was observed that ODN1 with unmethylated $\mathrm{CpG}$ motifs had immune stimulatory ability. However, induction of IFN- $\alpha$ by ODN1 could be abrogated when ODN1 was modified into non-CpG sequences or $\mathrm{C}$-methylated variations. The results of the present study confirmed that the immune stimulatory ability of Brucella REP is CpG dependent.

It is well-established that CpG ODNs may be recognized by TLR9 (19). The effects of ODN1 on the TLR9 signaling pathway were thus analyzed in the present study. It was observed that ODN1 significantly enhanced the expression of TLR9 at mRNA and protein levels. In addition, knockdown 

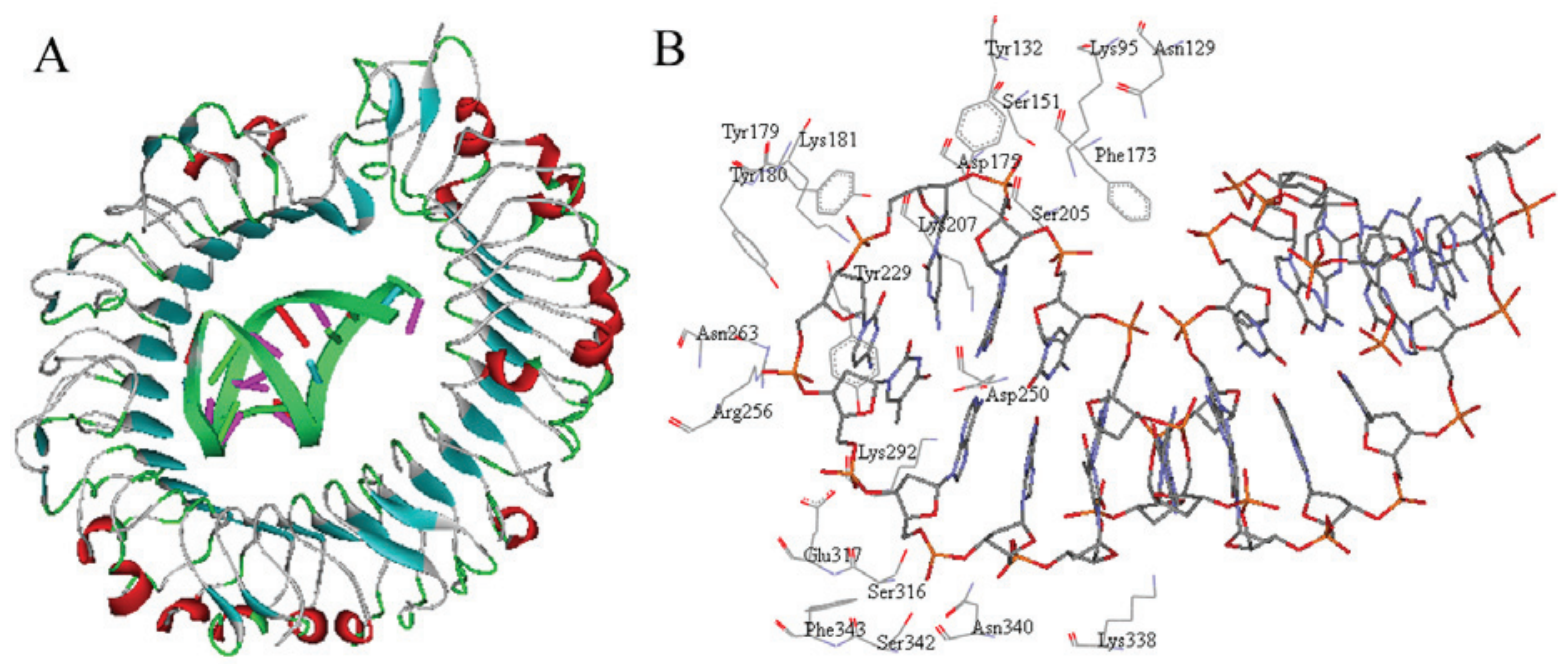

Figure 3. Interactions between TLR9 and ODN 1. (A) The predicted structure of the TLR9-ODN 1 complex obtained by molecular docking. (B) Illustration of the key residues involved in the binding of TLR9. ODN, oligodeoxynucleotide; TLR9, toll-like receptor 9.

A

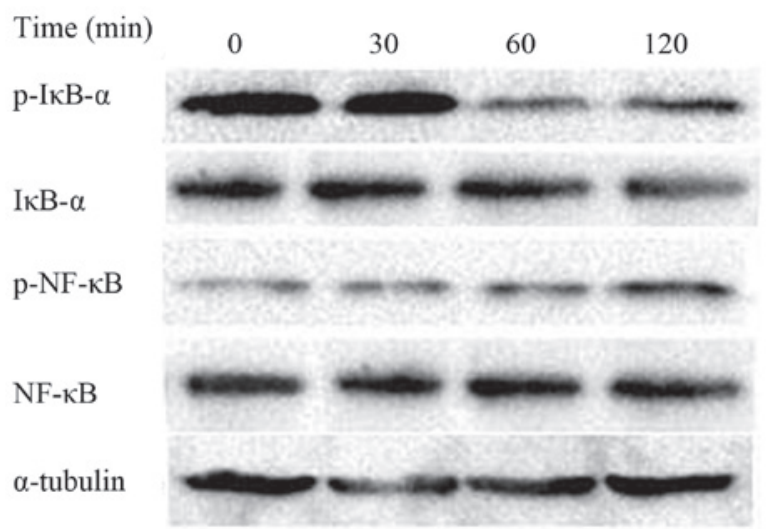

B

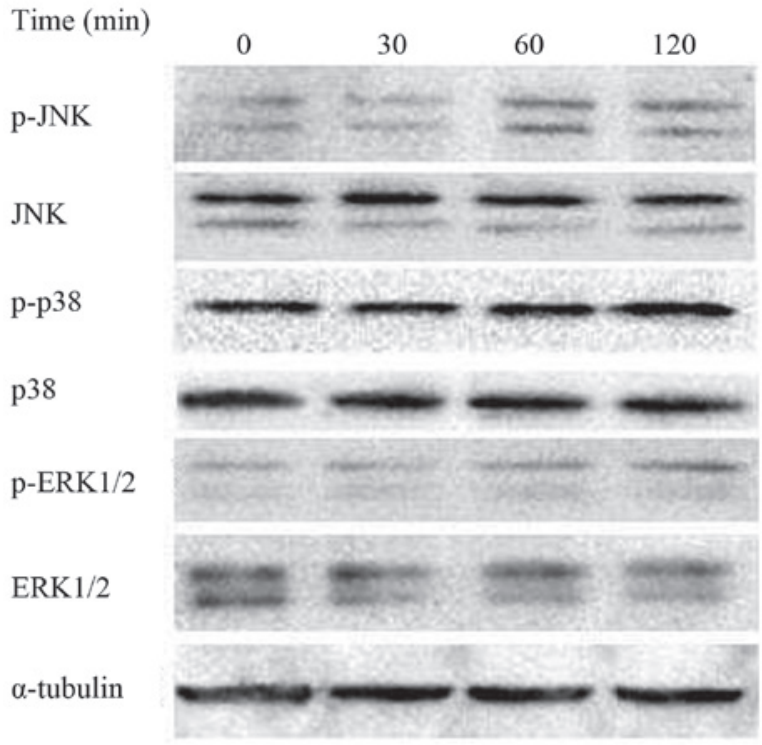

Figure 4. ODN 1-induced $\mathrm{I} \kappa \mathrm{B} / \mathrm{NF}-\kappa \mathrm{B}$ and MAPK signaling pathways in macrophages. (A) The protein expression levels of $\mathrm{p}-\mathrm{I} \kappa \mathrm{B}-\mathrm{a}, \mathrm{I \kappa} \mathrm{B}-\mathrm{a}$,

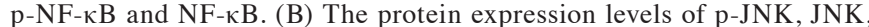
p-p38, p38, p-ERK1/2 and ERK1/2. Increased phosphorylation of JNK, p38 and ERK1/2 was observed. $\alpha$-tubulin served as the loading control. ODN, oligodeoxynucleotide; I $\mathrm{I}$, inhibitor of $\kappa \mathrm{B}$; NF- $\kappa \mathrm{B}$, nuclear factor- $\kappa \mathrm{B}$; MAPK, mitogen-activated protein kinase; p, phosphorylated; JNK, c-Jun $\mathrm{N}$-terminal kinase; ERK, extracellular signal-regulated kinase. of TLR9 expression by siRNA in macrophages led to a reduction of IFN- $\alpha$ production following REP stimulation. These results support the notion that, similar to other CpG ODNs, Brucella REP is able to activate macrophages through TLR9, consequently upregulating IFN- $\alpha$.

To improve our understanding of the mechanism of TLR9Brucella REP recognition, the interacting features between TLR9 and ODN1 were examined using molecular modeling approaches. The interaction pattern demonstrated that $>20$ residues in TLR9 were important for ligand recognition, and these residues established direct contact with ODN1. This is in agreement with the results of previous studies $(16,17)$.

Furthermore, the role of NF- $\kappa \mathrm{B}$ and MAPK signaling pathways in Brucella REP-mediated innate immune responses was determined. The present results revealed that the levels of the NF- $\mathrm{kB}$ p 65 phosphorylation were increased in macrophages stimulated with ODN1. A simultaneous decrease in the phosphorylation of IкB- $\alpha$ was also observed. In addition, the phosphorylation levels of p38, ERK1/2 and JNK were increased in ODN1-treated cells. These data suggest that the activation of the NF- $\mathrm{KB}$ and MAPK signaling pathways may in part contribute to the immunological response induced by Brucella REP.

In conclusion, the present study suggests that TLR9 recognizes and responds to Brucella REP, leading to the activation of downstream signaling pathways, including NF- $\kappa \mathrm{B}$ and MAPK, which then induce IFN- $\alpha$ biosynthesis. The finding that Brucella REPs are natural TLR9 agonists may be useful for the development of novel therapeutic applications.

\section{Acknowledgements}

The present study was supported by the National Natural Science Foundation of China (grant no., 81460049), the Natural Science Foundation of Inner Mongolia Autonomous Region of China (grant nos., 2014JQ04 and 2015MS0810) and the Program for Young Talents of Science and Technology in Universities of Inner Mongolia Autonomous Region of China (grant no., NJYT-14-A13). 


\section{References}

1. Hoffmann $\mathrm{J}$ and Akira S: Innate immunity. Curr Opin Immunol 25: 1-3, 2013.

2. O'Neill LA, Golenbock D and Bowie AG: The history of Toll-like receptors-redefining innate immunity. Nat Rev Immunol 13 : 453-460, 2013.

3. Riad A, Westermann D, Escher F, Becher PM, Savvatis K, Lettau O, Heimesaat MM, Bereswill S, Volk HD, Schultheiss HP and Tschöpe C: Myeloid differentiation factor- 88 contributes to TLR9-mediated modulation of acute coxsackievirus B3-induced myocarditis in vivo. Am J Physiol Heart Circ Physiol 298: H2024-H2031, 2010.

4. Bauer S, Kirschning CJ, Häcker H, Redecke V, Hausmann S, Akira S, Wagner $\mathrm{H}$ and Lipford GB: Human TLR9 confers responsiveness to bacterial DNA via species-specific CpG motif recognition. Proc Natl Acad Sci USA 98: 9237-9242, 2001.

5. El Kebir D, József L, Pan W, Wang L and Filep JG: Bacterial DNA activates endothelial cells and promotes neutrophil adherence through TLR9 signaling. J Immunol 182: 4386-4394, 2009.

6. Jurk M, Kritzler A, Debelak H, Vollmer J, Krieg AM and Uhlmann E: Structure-activity relationship studies on the immune stimulatory effects of base-modified CpG toll-like receptor 9 agonists. ChemMedChem 1: 1007-1014, 2006.

7. Yu D, Putta MR, Bhagat L, Li Y, Zhu F, Wang D, Tang JX, Kandimalla ER and Agrawal S: Agonists of Toll-like receptor 9 containing synthetic dinucleotide motifs. J Med Chem 50 6411-6418, 2007.

8. Moreno E, Cloeckaert A and Moriyón I: Brucella evolution and taxonomy. Vet Microbiol 90: 209-227, 2002.

9. Galińska EM and Zagórski J: Brucellosis in humans-etiology, diagnostics, clinical forms. Ann Agric Environ Med 20: 233-238, 2013.

10. Deghelt M, Mullier C, Sternon JF, Francis N,Laloux G, Dotreppe D, Van der Henst C, Jacobs-Wagner C, Letesson JJ and De Bolle X: G1-arrested newborn cells are the predominant infectious form of the pathogen Brucella abortus. Nat Commun 5: 4366, 2014.
11. Campos PC, Gomes MT, Guimarães G, Costa Franco MM, Marim FM and Oliveira SC: Brucella abortus DNA is a major bacterial agonist to activate the host innate immune system. Microbes Infect 16: 979-984, 2014

12. Gomes MT, Campos PC, de Almeida LA, Oliveira FS, Costa MM, Marim FM, Pereira GS and Oliveira SC: The role of innate immune signals in immunity to Brucella abortus. Front Cell Infect Microbiol 2: 130, 2012.

13. Huang LY, Ishii KJ, Akira S, Aliberti J and Golding B: Th1-like cytokine induction by heat-killed Brucella abortus is dependent on triggering of TLR9. J Immunol 175: 3964-3970, 2005.

14. Messing SA, Ton-Hoang B, Hickman AB, McCubbin AJ, Peaslee GF, Ghirlando R, Chandler M and Dyda F: The processing of repetitive extragenic palindromes: The structure of a repetitive extragenic palindrome bound to its associated nuclease. Nucleic Acids Res 40: 9964-9979, 2012.

15. Magnusson M, Tobes R, Sancho J and Pareja E: Cutting edge: Natural DNA repetitive extragenic sequences from gramnegative pathogens strongly stimulate TLR9. J Immunol 179: 31-35, 2007.

16. Ohto U, Shibata T, Tanji H, Ishida H, Krayukhina E, Uchiyama S, Miyake K and Shimizu T: Structural basis of $\mathrm{CpG}$ and inhibitory DNA recognition by Toll-like receptor 9. Nature 520: 702-705, 2015.

17. Zhou W, Li Y, Pan X, Gao Y, Li B, Qiu Z, Liang L, Zhou H and Yue J: Toll-like receptor 9 interaction with CpG ODN-an in silico analysis approach. Theor Biol Med Model 10: 18, 2013.

18. Nunvar J, Huckova T and Licha I: Identification and characterization of repetitive extragenic palindromes (REP)-associated tyrosine transposases: Implications for REP evolution and dynamics in bacterial genomes. BMC Genomics 11: 44, 2010

19. Suwarti S, Yamazaki T, Svetlana C and Hanagata N: Recognition of $\mathrm{CpG}$ oligodeoxynucleotides by human Toll-like receptor 9 and subsequent cytokine induction. Biochem Biophys Res Commun 430: 1234-1239, 2013. 